\title{
Perencanaan Pipa Dua Fasa pada Fasilitas Produksi Panas Bumi Dieng
}

\author{
Ady Setya Nugroho \\ PT. PLN (Persero) \\ Coresponding author email: Adhie1nugros@gmail.com
}

\begin{abstract}
Abstrak
Lapangan Panas Bumi Dieng beroperasi sejak tahun 2004 dengan kapasitas turbin 60 MW serta memiliki target produksi sebesar 55 MW selama tigapuluh tahun. Lapangan ini, masih layak untuk dilakukan pengembangan dengan total sebesar 110 MW. Dalam mengoptimalkan kualitas uap (steam quality) dari kepala sumur sampai dengan input turbin maka perlu adanya perencanan mengenai dimensi dari pipa yang mengalirkan uap. Parameter yang diperhatikan dalam perencanaan pipa dua fasa yaitu diameter pipa dan penurunan tekanan. Tujuan penelitian adalah menentukan diameter pipa dua fasa dan penurunan tekanan pada salah satu sumur pengembangan lapangan Panas Bumi Dieng. Metodologi perhitungan dimensi pipa ini menggunakan standar ASME dalam penentuan diameter pipa dan menghitung besarnya penurunan tekanan sebelum input turbin menggunakan software pipesim. Hasil perhitungan salah satu sumur yang memiliki masa aliran sebesar $60 \mathrm{~kg} / \mathrm{s}$ didapatkan jenis pipa Xtra Strong (XS) kualitas uap 0.176 dengan diameter pipa 8 inchi serta kecepatan aliran yang optimal sebesar $27.33 \mathrm{~m} / \mathrm{s}$ serta penurunan tekanan dari well head menuju separator adalah 7 , 476 bar dengan tekanan input turbin sebesar 22,985 bar.
\end{abstract}

Kata kunci : perencanaan, pipa, dua fasa, fasilitas produksi.

\section{Abstract}

Dieng Geothermal Field operates since 2004 with a 60 MW turbine capacity and has a production target of 55 MW for thirty years. This field is still feasible for development with a total of $110 \mathrm{MW}$. In optimizing the quality of steam (steam quality) from the wellhead to the turbine input, it is necessary to plan on the dimensions of the pipe that flows steam. Parameters that are considered in planning two-phase pipes are pipe diameter and pressure drop. The research objective was to determine the two-phase pipe diameter and pressure drop at one of the wells in the Dieng Geothermal field development. The methodology for calculating the pipe dimensions uses the ASME standard in determining pipe diameter and calculating the amount of pressure drop before the turbine input using pipesim software. The calculation results of one well that has a flow period of $60 \mathrm{~kg} / \mathrm{s}$ obtained Xtra Strong (XS) pipe type vapor quality 0.176 with 8 inch pipe diameter and optimal flow velocity of $27.33 \mathrm{~m} / \mathrm{s}$ and pressure drop from well head to separator is 7 , 476 bars with turbine input pressure of 22,985 bars.

Keywords: planning, pipeline, two phase, production facilities.

\section{Pendahuluan}

Dieng yang berlokasi di Provinsi Jawa Tengah merupakan salah satu lokasi proyek Pembangkit Listrik Tenaga Panas Bumi (PLTP) Geo Dipa Energi. Dengan kontur pegunungan, sumber air panas, solfatara, fumarole serta bebatuan mengindikasikan bahwa Dieng merupakan lokasi yang potensial untuk dikembangkan sebagai sumber energi panas bumi. Total potensi energi panas bumi di sekitar Dieng diperkirakan sebesar $400 \mathrm{MW}$.

Dieng Unit 1, dengan kapasitas terpasang 60 MW, selesai pada Juli 1998 tetapi tidak dibawa ke dalam operasi komersial karena dikeluarkannya Keputusan Presiden No. 5/98 yang menunda proyek dieng serta beberapa proyek lainnya. Pembangunan Dieng Unit II juga ditangguhkan pada tahun 1998. Pada tahun 2002, komisioning kembali Dieng Unit I dilakukan di bawah Geo Dipa
Energi dan pada September 2002. Unit Dieng 1 mulai beroperasi secara komersial. Sampai sekarang, Dieng Unit I terdiri dari sembilan sumur HCE yang berlokasi di sektor Sileri; untuk keperluan injeksi menggunakan sumur satu HCE di Sileri dan 4 sumur Pertamina di sektor Sileri dan Sikidang.( Sirait P, dkk. 2015)

Saat ini, Geo Dipa Energi berhasil mengoperasikan proyek Dieng Unit 1 dengan kapasitas sebesar $60 \mathrm{MW}$ yang terhubung ke jaringan JawaMadura-Bali melalui system interkoneksi. Selain itu, untuk memenuhi target usaha dilakukan peningkatan serta pengembangan kapasitas proyek Dieng 2 dan 3, masing-masing berkapasitas 55 MW. Banyaknya sumur di lapangan Dieng memberikan ketersediaan data teknis yang lebih tinggi sehingga dapat lebih meningkatkan success ratio pemboran. 
Dalam mengoptimalkan kualitas uap (steam quality) dari kepala sumur sampai dengan input turbin maka perlu adanya Analisa mengenai dimensi dari pipa yang mengalirkan uap. Pipa dua fasa merupakan hal yang sangat penting karena dalam aliran dua fasa memiliki penurunan tekanan yang cukup besar. Dengan kecepatan aliran dua fasa yang ideal adalah $20-30 \mathrm{~m} / \mathrm{s}$. Aplikasi pipesim dapat mengetahui penurunan tekanan, temperatur dan kualitas uap fluida dalam pipa.

Pola aliran dalam pipa horizontal terlihat pada Gambar 1, antara lain :

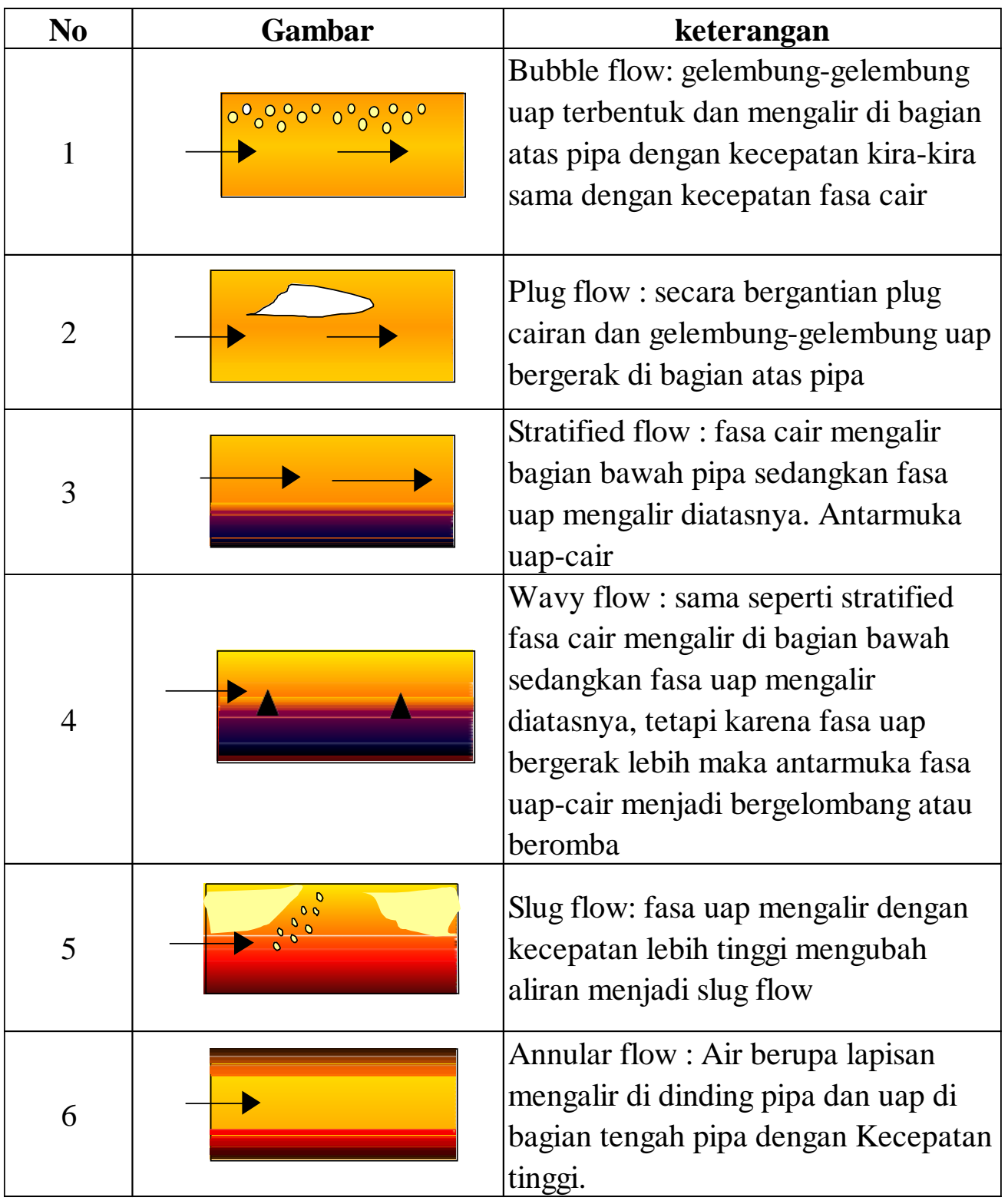

Gambar 1. Pola Aliran Pipa Horisontal di Panas Bumi

Batas kecepatan dalam pipa aliran dua fasa dan aliran perlu ditetapkan, batas kecepatan minimal menggambarkan batas perpindahan panas untuk mencapai proses adiabatis, sedangkan batas kecepatan maksimum menyatakan batas tidak terjadi pengikisan dinding pipa bagian dalam. Batas kecepatan pada pipa aliran dua fasa, batas minimal $20 \mathrm{~m} / \mathrm{s}$ dan batas maksimal $30 \mathrm{~m} / \mathrm{s}$.
Parameter-parameter yang perlu diketahui terlebih dahulu adalah sebagai berikut :

- Massa Fluida (Liquid dan Steam)

- Kualitas Uap

- Mix Enthalpy

- Mix Spesific Volume 
Sedangkan parameter yang menentukan optimasi yang diperlukan dari keluaran simulator PipeSim adalah sebagai berikut :

1. Diameter (dalam) pipa alir dua fasa (m).

2. Kecepatan rata-rata aliran pada pipa dua fasa $(\mathrm{m} / \mathrm{s})$.

3. Kehilangan tekanan pada pipa dua fasa (bar).

4. Temperatur pada input separator $\left({ }^{\circ} \mathrm{C}\right)$.

5. Daya yang ditimbulkan (MW).

6. Nilai uang saat ini karena investasi pipa salur (\$)

\section{Metodologi}

Perhitungan dimensi pipa ini menggunakan standar ASME tentang standar pipa yang sesuai dan kemudian dilakukan perbandingan penurunan tekanan menggunakan software pipesim.

Tahapan dalam menentukan dimensi pipa dua fasa adalah :

1. Menentukan Di (diameter dalam) Sementara Kecepatan aliran dalam pipa air tergantung pada ukuran pipa dan laju aliran. Jika laju aliran seragam di seluruh pipa (aliran tetap), kecepatan di setiap bagian lintas sepanjang pipa akan menjadi nilai konstan. Namun, ada variasi kecepatan di sepanjang penampang pipa. Kecepatan di dinding pipa akan nol, meningkat secara maksimal di garis tengah pipa.

$$
\text { Velocity }=\frac{\text { flow rate }}{\text { area of flow }} \ldots . . .
$$

Karena area aliran dalam pipa adalah lingkaran maka persamaannya menjadi :

$$
\mathrm{V}=\frac{\mathrm{m} \times V m}{\frac{1}{4} \times \pi \times D i^{2}}
$$

dengan :

$$
\begin{aligned}
\mathrm{V} & =\text { Velocity }(\mathrm{m} / \mathrm{s}) \\
\mathrm{M} & =\text { massa fluida }(\mathrm{kg} / \mathrm{s}) \\
\mathrm{Vm} & =\text { Viskositas mix } \\
\mathrm{Di} & =\text { Diameter dalam }(\mathrm{m})
\end{aligned}
$$

Perhitungan Viskostas mix (campuran) adalah dengan persamaan :

$$
V m=x V g+(1-x) V l
$$

dengan :

$\mathrm{Vm}=$ Viskositas Campuran

$\mathrm{X}=$ Kualitas Uap (Steam Quality)
$\mathrm{Vg}=$ Viskositas gas

$\mathrm{Vl}=$ Viskositas liquid

2. Menentukan perencanaan pipa dengan jenis XS (Xtra strong)

Berdasarkan ASME B36.10M bisa dilihat tabel schedule pipa, pada pembangkit panas bumi yang mempunyai karakteristik suhu yang tinggi pada umumnya digunakan jenis XS (Xtra Strong).

3. Menghitung tebal minimum kemudian disinkronisasi dengan schedule pipe

Menurut ASME 31.1 ketebalan dinding minimum yang diperlukan untuk tekanan desain dan untuk suhu yang tidak melebihi nilai tegangan yang diperbolehkandari bahan yang dipergunakan.

$$
\begin{aligned}
& \mathrm{tm}=\frac{\mathrm{P} \times D o}{2 \times(\operatorname{Sh} E+P y)}+A \\
& \text { dengan: } \\
& \mathrm{Tm}=\text { ketebalan pipa yang diperlukan } \\
& \mathrm{P}=\text { tekanan yang direncanakan } \\
& \text { Do }=\text { diameter luar pipa }(\mathrm{m}) \\
& \mathrm{Sh}=\underset{\text { pada suhu desain }}{\text { tegangan material yang diizinkan }} \\
& \mathrm{E}=\text { faktor pengelasan, } 1 \\
& \mathrm{Y}=\text { koefisien, untuk pipa dengan } \\
& \mathrm{T}<482^{\circ} \mathrm{C} \text { menggunakan } 0.4 \\
& \mathrm{~A}=\text { corrosion allowable, dalam panas } \\
& \text { bumi biasanya } 0.003 \mathrm{~m}
\end{aligned}
$$

4. Menghitung kecepatan aliran fluida dalam pipa

\section{Hasil dan Pembahasan}

Data yang dibutuhkan dalam menjalankan simulator pipesim antara lain :

$\begin{array}{ll}\text { PWH } & : 18.8 \mathrm{bar} \\ \text { Panjang pipa } & : 250 \mathrm{~m} \\ \text { Steam quality } & : 0,23 \\ \text { Massa total } & : 79 \mathrm{~kg} / \mathrm{s} \\ \text { Temperatur lingkungan } & : 19^{\circ} \mathrm{C}\end{array}$


Data material dan lapangan antara lain data sebagai input dalam aplikasi pipesim terlihat pada Gambar 2.

\begin{tabular}{|c|c|c|}
\hline Kharakter & Pipa & Isolasi \\
\hline Konduktivitas $\left(\mathrm{w} / \mathrm{m}^{\circ} \mathrm{C}\right)$ & 54 & 0.0677 \\
\hline Kekasaran pipa $(\mathrm{m})$ & 0.00005 & - \\
\hline Matrial & Baja karbon rendah & \\
\hline & API 5L grade B, A106 & Calcium silica \\
\hline Jenis Pipa & Grade B, A53 Grade B & \\
\hline Xs (extra strongth), & \\
\hline Densitas pipa $\left(\mathrm{kg} / \mathrm{m}^{3}\right)$ & Electric Resistant & - \\
\hline
\end{tabular}

Gambar 2. Spesifikasi Material

Dalam melakukan desain pipa dua fasa, yaitu dari wellhead ke separator, maka terlebih dahulu dilakukan pembuatan layout dari wellhead ke separator yang nantinya akan dijadikan tahapan dalam perhitungan pada masing -masing segmen.

Input data pada sumur adalah :

PWH : 30,46 bar

Panjang pipa $\quad: 130 \mathrm{~m}$

Dryness : : 0,176

Massa total $\quad: 60 \mathrm{~kg} / \mathrm{s}$

Temperatur lingkungan : $19^{\circ} \mathrm{C}$

Diameter pipa :

Diameter pipa disesuaikan dengan perhitungan terhadap jenis fluida, tekanan fluida dan batas kecepatan fluida.

Roughness :

Comersial Steel Pipe $=0,00005 \mathrm{~m}$

Tahapan menghitung diameter pipa dua fasa adalah tahapan dalam menentukan dimensi yaitu :

1. Menentukan Di (diameter dalam) Sementara

$$
\mathrm{V}=\frac{\mathrm{m} \times V m}{\frac{1}{4} \times \pi \times D i^{2}}
$$

Persamaan diatas digunakan untuk mencari diameter dalam pipa, dengan diketahui data :

$$
\mathrm{V} \quad: 30 \mathrm{~m} / \mathrm{s}
$$

$$
\begin{array}{ll}
\text { Massa } & : 60 \mathrm{~kg} / \mathrm{s} \\
\mathrm{Vm} & : 0.01342 \mathrm{~m} 3 / \mathrm{kg}
\end{array}
$$

2. Menghitung Spesific Volume (Vm) adalah specific volume campuran antara steam dan water dengan menggunakan persamaan :

$$
V m=x V g+(1-x) V l
$$

pada x (kualitas uap) sebesar 0.176 maka dengan melihat steam table diketahui :

$$
\begin{array}{ll}
\mathrm{Vg} & =0.058878 \\
\mathrm{Vl} & =0.001231
\end{array}
$$

Sehingga :

$$
V m=0.176 \times 0.058878+(1-
$$

$$
\text { 0.176) } \times 0.001231
$$

$$
V m=0.013418868
$$

Sehingga diameter dalam pipa sementara adalah :

$$
\begin{aligned}
& V=\frac{60 \times 0.01342}{\frac{1}{4} \times \frac{22}{7} \times D i^{2}} \\
& 30=\frac{60 \times 0.01342}{\frac{1}{4} \times \frac{22}{7} \times D i^{2}}
\end{aligned}
$$

Maka Di (diameter dalam) sementara adalah :

$$
\begin{aligned}
\text { Di }(\text { sementara }) & =0.18490 \mathrm{~m} \\
& =7.27955 \mathrm{inch}
\end{aligned}
$$




$$
=184.9005 \mathrm{~mm}
$$

3. Menentukan Schedule pipa dengan jenis XS (Xtra strong).

Sesuai dengan kondisi tekanan dan temperatur yang tinggi maka dipilihlah Schedule pipa dengan jenis XS (xtra strong).
Dengan melihat perhitungan diameter dalam pipa adalah 7,27 in maka dipilih pipa schedule berdasarkan ASME B36.10M (dipilih diameter yang diatas perhitungan) terlihat pada tabel 1 yaitu :

Tabel 1. Pipe Schedule standar ASME B36.10M

\begin{tabular}{||cl|c|c|c||}
\hline \multicolumn{1}{|c|}{ Carbon steel (dn, Imperial units) } & Dn $=$ & 8 & in \\
\hline $\mathrm{d}_{\mathrm{i}}=$ & Pipe_Imp_CS_Dint_dn_sch & $\mathrm{d}_{\mathrm{i}}=$ & 193.7 & $\mathrm{~mm}$ \\
$\mathrm{~d}_{\mathrm{e}}=$ & Pipe_Imp_CS_Dext_dn & $\mathrm{d}_{\mathrm{e}}=$ & 219.1 & $\mathrm{~mm}$ \\
$\mathrm{~S}=$ & Pipe_Imp_CS_Thickness_dn_sch & $\mathrm{s}=$ & 12.7 & $\mathrm{~mm}$ \\
\hline
\end{tabular}

\begin{tabular}{|c|c|c|c|c|c|c|c|c|c|c|c|c|c|c|c|c|}
\hline \multirow{3}{*}{$\frac{\mathrm{dn}}{\mathrm{mm}}$} & \multirow{3}{*}{$\frac{d n}{n}$} & \multirow{3}{*}{$\begin{array}{c}\mathrm{d}_{\mathrm{ext}} \\
\mathrm{mm}\end{array}$} & \multicolumn{14}{|c|}{ Carbon steel pipe thickness $\mathrm{s}(\mathrm{mm})$} \\
\hline & & & \multicolumn{14}{|c|}{ ASME B36.10M SCHEDULE } \\
\hline & & & 5 & 10 & 20 & 30 & 40 & 60 & 80 & 100 & 120 & 140 & 160 & STD & Xs & xxs \\
\hline 6 & $1 / 8$ & 10.3 & 0 & 1.24 & 0 & 1.45 & 1.73 & 0 & 2.41 & 0 & 0 & 0 & 0 & 0 & 0 & 0 \\
\hline 8 & $1 / 4$ & 13.7 & 0 & 1.65 & 0 & 1.85 & 2.24 & 0 & 3.02 & 0 & 0 & 0 & 0 & 0 & 0 & 0 \\
\hline 10 & $3 / 8$ & 17.1 & 0 & 1.65 & 0 & 1.85 & 2.31 & 0 & 3.2 & 0 & 0 & 0 & 0 & 0 & 0 & 0 \\
\hline 15 & $1 / 2$ & 21.3 & 1.65 & 2.11 & 0 & 2.41 & 2.77 & 0 & 3.73 & 0 & 0 & 0 & 4.78 & 2.77 & 3.73 & 7.47 \\
\hline 20 & $3 / 4$ & 26.7 & 1.65 & 2.11 & 0 & 2.41 & 2.87 & 0 & 3.91 & 0 & 0 & 0 & 5.56 & 2.87 & 3.91 & 7.82 \\
\hline 25 & 1 & 33.4 & 1.65 & 2.77 & 0 & 2.9 & 3.38 & 0 & 4.55 & 0 & 0 & 0 & 6.35 & 3.38 & 4.55 & 9.09 \\
\hline 32 & $11 / 4$ & 42.2 & 1.65 & 2.77 & 0 & 2.97 & 3.56 & 0 & 4.85 & 0 & 0 & 0 & 6.35 & 3.56 & 4.85 & 9.7 \\
\hline 40 & $11 / 2$ & 48.3 & 1.65 & 2.77 & 0 & 3.18 & 3.68 & 0 & 5.08 & 0 & 0 & 0 & 7.14 & 3.68 & 5.08 & 10.15 \\
\hline 50 & 2 & 60.3 & 1.65 & 2.77 & 0 & 3.18 & 3.91 & 0 & 5.54 & 0 & 0 & 0 & 8.74 & 3.91 & 5.54 & 11.07 \\
\hline 65 & $21 / 2$ & 73.0 & 2.11 & 3.05 & 0 & 4.78 & 5.16 & 0 & 7.01 & 0 & 0 & 0 & 9.53 & 5.16 & 7.01 & 14.02 \\
\hline 80 & 3 & 88.9 & 2.11 & 3.05 & 0 & 4.78 & 5.49 & 0 & 7.62 & 0 & 0 & 0 & 11.13 & 5.49 & 7.62 & 15.24 \\
\hline 90 & $3 \quad 1 / 2$ & 101.6 & 2.11 & 3.05 & 0 & 4.78 & 5.74 & 0 & 8.08 & 0 & 0 & 0 & - & 5.74 & 8.08 & - \\
\hline 100 & 4 & 114.3 & 2.11 & 3.05 & 0 & 4.78 & 6.02 & 0 & 8.56 & 0 & 0 & 0 & 13.49 & 6.02 & 8.56 & 17.12 \\
\hline 125 & 5 & 141.3 & 2.77 & 3.4 & 0 & 0 & 6.55 & 0 & 9.53 & 0 & 0 & 0 & 15.88 & 6.55 & 9.53 & 19.05 \\
\hline 150 & 6 & 168.3 & 2.77 & 3.4 & 0 & 0 & 7.11 & 0 & 10.97 & 0 & 0 & 0 & 18.26 & 7.11 & 10.97 & 21.95 \\
\hline 200 & 8 & 219.1 & 2.77 & 3.76 & 6.35 & 7.04 & 8.18 & 10.31 & 12.7 & 15.09 & 18.26 & 20.62 & 23.01 & 8.18 & 12.7 & 22.23 \\
\hline 250 & 10 & 273 & 3.40 & 4.19 & 6.35 & 7.8 & 9.27 & 12.7 & 15.09 & 18.26 & 21.44 & 25.4 & 28.58 & 9.27 & 12.7 & 25.4 \\
\hline 300 & 12 & 323.8 & 3.96 & 4.57 & 6.35 & 8.38 & 10.31 & \begin{tabular}{|l|l}
14.27 \\
\end{tabular} & 17.48 & 21.44 & 25.4 & 28.58 & 33.32 & 9.53 & 12.7 & 25.4 \\
\hline 350 & 14 & 355.6 & 3.96 & 6.35 & 7.92 & 9.53 & 11.13 & 15.09 & 19.05 & 23.83 & 27.79 & 31.75 & 35.71 & 9.53 & 12.7 & 0 \\
\hline 400 & 16 & 406.4 & 4.19 & 6.35 & 7.92 & 9.53 & 12.7 & 16.66 & 21.44 & 26.19 & 30.96 & 36.53 & 40.49 & 9.53 & 12.7 & 0 \\
\hline 450 & 18 & 457 & 4.19 & 6.35 & 7.92 & 11.13 & 14.27 & 19.05 & 23.83 & 29.36 & 34.93 & 39.67 & 45.24 & 9.53 & 12.7 & 0 \\
\hline 500 & 20 & 508 & 4.78 & 6.35 & 9.53 & 12.7 & 15.09 & 20.62 & 26.19 & 32.54 & 38.1 & 44.45 & 50.01 & 9.53 & 12.7 & 0 \\
\hline 550 & 22 & 559 & 4.78 & 6.35 & 9.53 & 12.7 & 0 & 22.23 & 28.58 & 34.93 & 41.28 & 47.63 & 53.98 & 9.53 & 12.7 & 0 \\
\hline 600 & 24 & 610 & 5.54 & 6.35 & 9.53 & 14.27 & 17.48 & 24.61 & 30.96 & 38.89 & 46.02 & 52.37 & 59.54 & 9.53 & 12.7 & 0 \\
\hline 650 & 26 & 660 & 0 & 7.92 & 12.7 & 15.88 & 0 & 0 & 0 & 0 & 0 & 0 & 0 & 9.53 & 12.7 & 0 \\
\hline 700 & 28 & 711 & 0 & 7.92 & 12.7 & 0 & 0 & 0 & 0 & 0 & 0 & 0 & 0 & 9.53 & 12.7 & 0 \\
\hline 750 & 30 & 762 & 6.35 & 7.92 & 12.7 & 15.88 & 0 & 0 & 0 & 0 & 0 & 0 & 0 & 9.53 & 12.7 & 0 \\
\hline 800 & 32 & 813 & 0 & 7.92 & 12.7 & 15.88 & 17.48 & 0 & 0 & 0 & 0 & 0 & 0 & 9.53 & 12.7 & 0 \\
\hline 850 & 34 & 864 & 0 & 7.92 & 12.7 & 15.88 & 17.48 & 0 & 0 & 0 & 0 & 0 & 0 & 9.53 & 12.7 & 0 \\
\hline 900 & 36 & 914 & 0 & 7.92 & 12.7 & 15.88 & 19.05 & 0 & 0 & 0 & 0 & 0 & 0 & 9.53 & 12.7 & 0 \\
\hline 950 & 38 & 965 & 0 & 0 & 0 & 0 & 0 & 0 & 0 & 0 & 0 & 0 & 0 & 9.53 & 12.7 & 0 \\
\hline 1000 & 40 & 1016 & 0 & 0 & 0 & 0 & 0 & 0 & 0 & 0 & 0 & 0 & 0 & 9.53 & 12.7 & 0 \\
\hline 1050 & 42 & 1067 & 0 & 0 & 0 & 0 & 0 & 0 & 0 & 0 & 0 & 0 & 0 & 9.53 & 12.7 & 0 \\
\hline 1100 & 44 & 1118 & 0 & 0 & 0 & 0 & 0 & 0 & 0 & 0 & 0 & 0 & 0 & 9.53 & 12.7 & 0 \\
\hline 1150 & 46 & 1168 & 0 & 0 & 0 & 0 & 0 & 0 & 0 & 0 & 0 & 0 & 0 & 9.53 & $\mid 12.7$ & 0 \\
\hline 1200 & 48 & 1219.2 & 0 & 0 & 0 & 0 & 0 & 0 & 0 & 0 & 0 & 0 & 0 & 9.53 & 12.7 & 0 \\
\hline
\end{tabular}

4. Menghitung Tebal minimum kemudian di cek dengan schedule pipa

Pengecekan dilakukan dengan menghitung tebal minimum pipa.

$$
\mathrm{tm}=\frac{\mathrm{P} \times D o}{2 \times(\operatorname{Sh} E+P y)}+A
$$

$$
\begin{aligned}
\mathrm{tm} & =\frac{30.46 \times 219.1}{2 \times(1379 \times 1+30.46 \times 0.4)}+3 \\
\mathrm{tm} & =5.409 \mathrm{~mm}
\end{aligned}
$$

Sehingga tebal minimum adalah $5.409 \mathrm{~mm}$, jika dibandingkan dengan tebal material Carbon 


\section{Perencanaan Pipa Dua Fasa pada Fasilitas Produksi Panas Bumi Dieng}

Steal Xstra Strong memiliki tebal sebesar 12.7 $\mathrm{mm}$. Sehingga ketebalanya memenuhi standar.

5. Menghitung kecepatan aliran fluida dalam pipa Setelah ditentukan dimensi pipa berdasarkan pipe schedule (Carbon Steel Xstra Strong) maka dihitung kecepatan fluida dalam pipa dengan persamaan :

$$
\begin{aligned}
& \mathrm{V}=\frac{\mathrm{m} \times V m}{\frac{1}{4} \times \pi \times D i^{2}} \\
& \mathrm{~V}=\frac{60 \times 0.01341}{\frac{1}{4} \times \pi \times D i^{2}}
\end{aligned}
$$

$$
\mathrm{V}=\frac{60 \times 0.01341}{\frac{1}{4} \times \pi \times D i^{2}}
$$

Maka diperoleh kecepatan aliran:

$$
\mathrm{V}=27,33 \mathrm{~m} / \mathrm{s}
$$

Untuk perhitungan kehilangan tekanan digunakan simulator pipesim. Hasil output simulator dapat ditunjukkan pada gambar 3 .

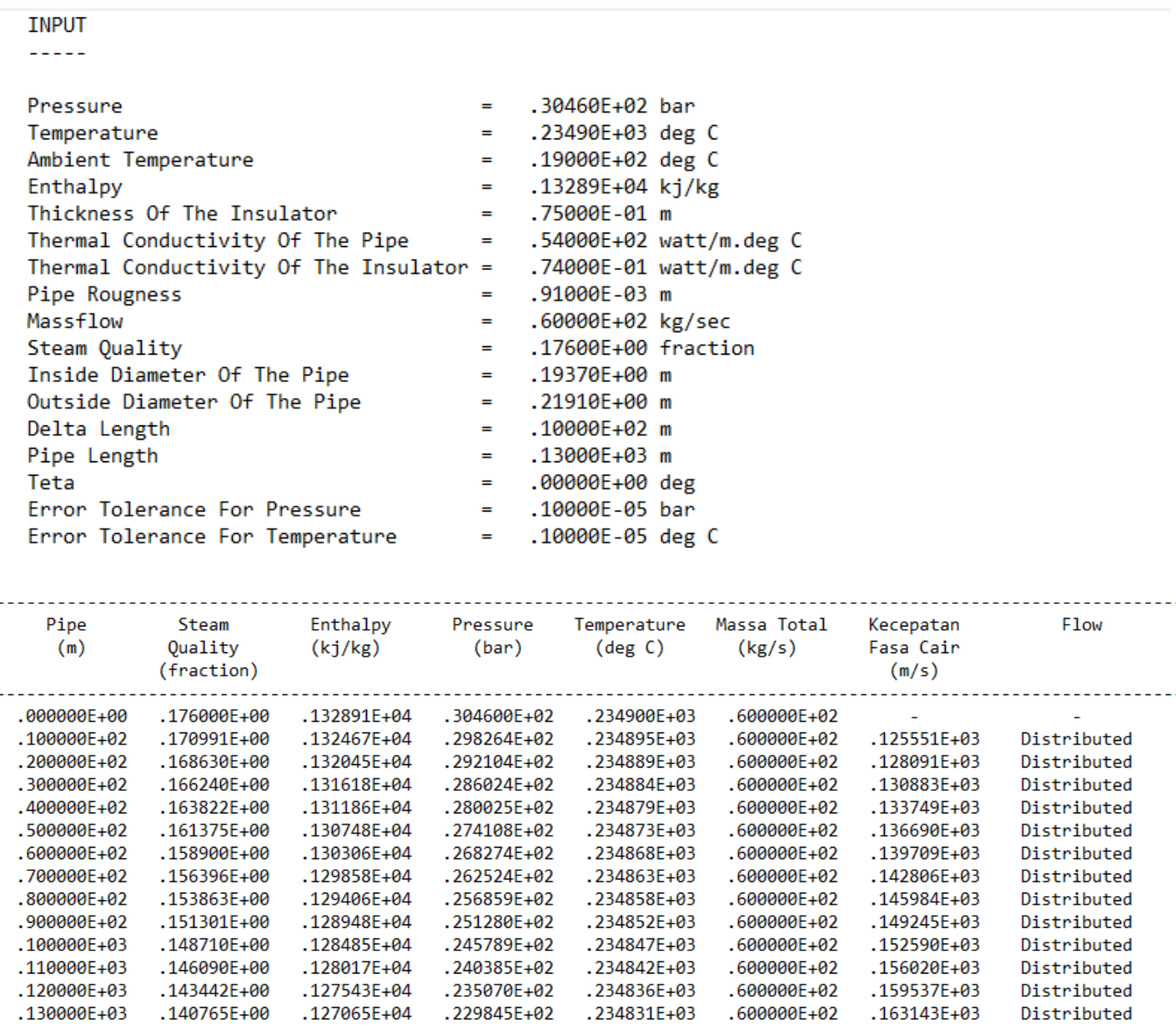

\section{Gambar 3. Hasil Ouput Simulator Pipesim}

Dari hasil output simulator pipesim didapatkan tekanan input pipa dari wellhead 30, 460 bar dan tekanan output pipa menuju turbin sebesar 22,985 bar maka diperoleh kehilangan tekanan sebesar 7 , 476 bar. 


\section{Kesimpulan}

1. Perhitungan diameter pipa sesuai standar ASME dengan diketahui masa sebesar $60 \mathrm{~kg} / \mathrm{s}$ dan kualitas uap sebesar 0.176 yaitu 8 inchi.

2. Penurunan tekanan dari well head menuju separator adalah 7, 476 bar dengan tekanan input turbin sebesar 22,985 bar sehingga diperlukan valve untuk menyesuaikan tekanan dengan spesifikasi turbin.

3. Kecepatan aliran yang memenuhi kondisi ideal antara $20-30 \mathrm{~m} / \mathrm{s}$ adalah $27.33 \mathrm{~m} / \mathrm{s}$.

\section{Daftar Pustaka}

Sirait P., Ridwan R. H., Battistelli A., 2015. Reservoir Modeling for Development $\mathrm{Ca}$ pacity of Dieng Geothermal Field, Indonesia. Proceedings Fortieths Workshop on Geothermal Reservoir Engineering Stanford University, Stanford, California, January 26-28.

Saptadji N. M., 1998. Teknik Panas Bumi. Kelompok Studi Panas Bumi, Institut Teknologi Bandung: Bandung. Chapter 10 page 1-12.

Sashi E. M., Piping Calculation Manual., 2005. Systek Technologies, Inc. New York. Chapter 4 Page 231-232.

ASME Code for Tekanan Piping, B31 dan B36. 